\title{
Adolescência e vulnerabilidade *
}

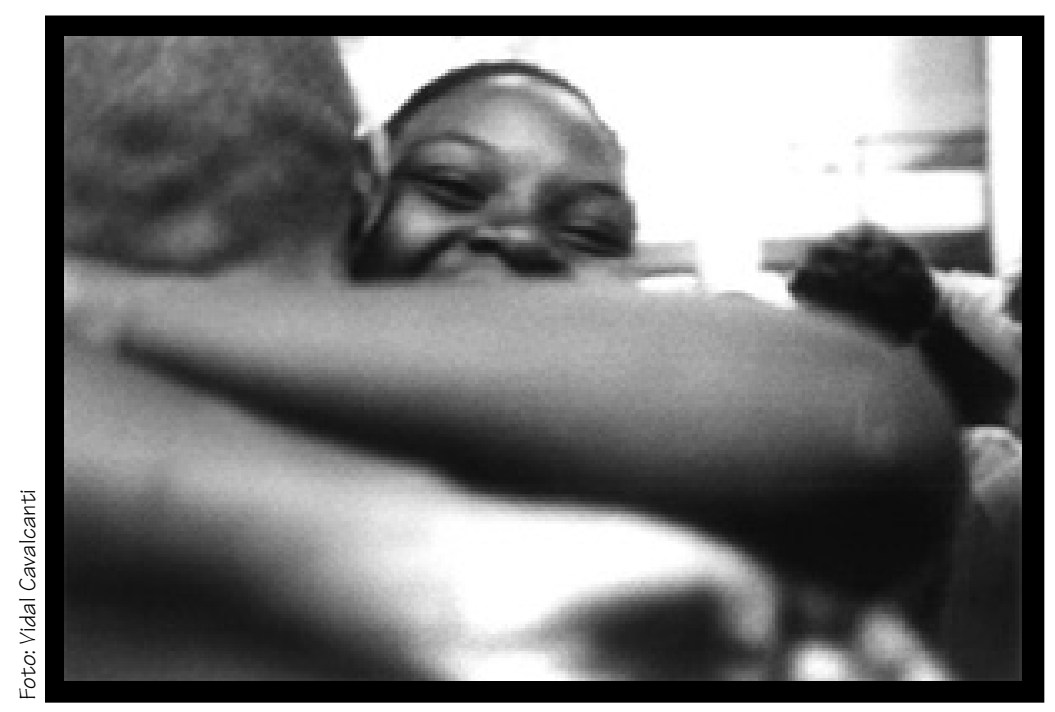

Elisabeth Maria Vieira Gonçalves ${ }^{1}$

Os adolescentes se encontram com adolescentes para conversar sobre vida, prazeres, medos, coragem, corpo, sexualidade. Falam sobre suas expectativas, seus projetos de vida e como se prevenir das DSTs (doenças sexualmente transmissíveis) e AIDS. Contam o que sabem. Discutem o que não sabem. Pensam, trocam idéias, expressam dúvidas e sentimentos relacionados à vivência da sexualidade. Aprendem uns com os outros. Chegam de diferentes regiões da cidade, vindos de diversos grupos $e$ segmentos sociais. Trabalham juntos.

* Álbum seriado produzido como material didático de apoio ao trabalho de multiplicadores na prevenção das DST e Aids, São Paulo, 1998.

${ }^{1}$ Coordenadora do Projeto "Trance essa Rede", Grupo de Trabalho e Pesquisa em Orientação Sexual (GTPOS). <gtpos@that.com.br> 
Este é o Projeto TRANCE ESSA REDE, financiado pelo Ministério da Saúde e coordenado pelo GTPOS - Grupo de Trabalho e Pesquisa em Orientação Sexual - desde 1996, que visa a construção de uma rede de ações educativas, desenvolvidas por adolescentes multiplicadores, na área da sexualidade e prevenção das DST/Aids.

Os adolescentes multiplicadores reúnem-se, semanalmente, com outros adolescentes, em grupos de trabalho, oficinas e participam de grupos de supervisão com educadores e técnicos do GTPOS. Neste processo de multiplicação de ações educativas, os adolescentes visualizam as propostas de intervenção, participando desde o planejamento, a realização, até a avaliação das ações. Os seus questionamentos incluem principalmente discussão de valores, preconceitos, mitos, modelos e estereótipos que envolvem o exercício da sexualidade; as relações homo/hetero/bissexuais; a gravidez na adolescência e a responsabilidade dos adolescentes, garotos e garotas, nos cuidados com sua saúde sexual e a do outro.

Esta experiência tem estimulado espaços de debate e de convivência, promovendo a atuação dos jovens como SUJEITOS capazes de intervir e transformar a realidade em que vivem. Reconhecem a importância da promoção da saúde e a prevenção da Aids como direito constitutivo da cidadania.

A idéia do Álbum ADOLESCÊNCIA E VULNERABILIDADE surgiu nesses encontros. Foi produzido para dar apoio aos educadores e adolescentes para o trabalho de multiplicação. A partir de imagens, conceitos e atividades, os educadores podem criar e recriar, transformando o álbum em veículo de comunicação, ação e, portanto, de prevenção. Pode ser usado nos espaços da escola, da comunidade, enfim, em qualquer lugar que reúna grupos de adolescentes. A imagem, estratégia norteadora do material, pretende ser um estímulo disparador de discussão sobre os vários aspectos que vulnerabilizam o adolescente frente à infecção pelo HIV e outras DSTs.

A tiragem inicial do Álbum, coordenada pelo GTPOS, foi de três mil exemplares, tendo o Ministério da Saúde - CN DST/Aids impresso outros vinte mil para distribuição gratuita para todo território nacional.

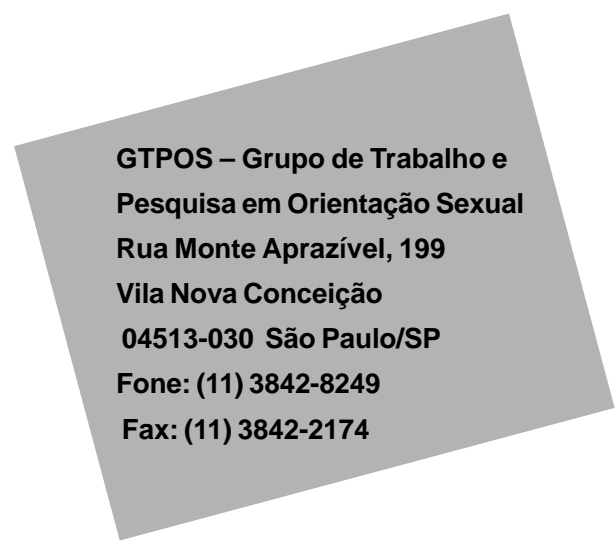




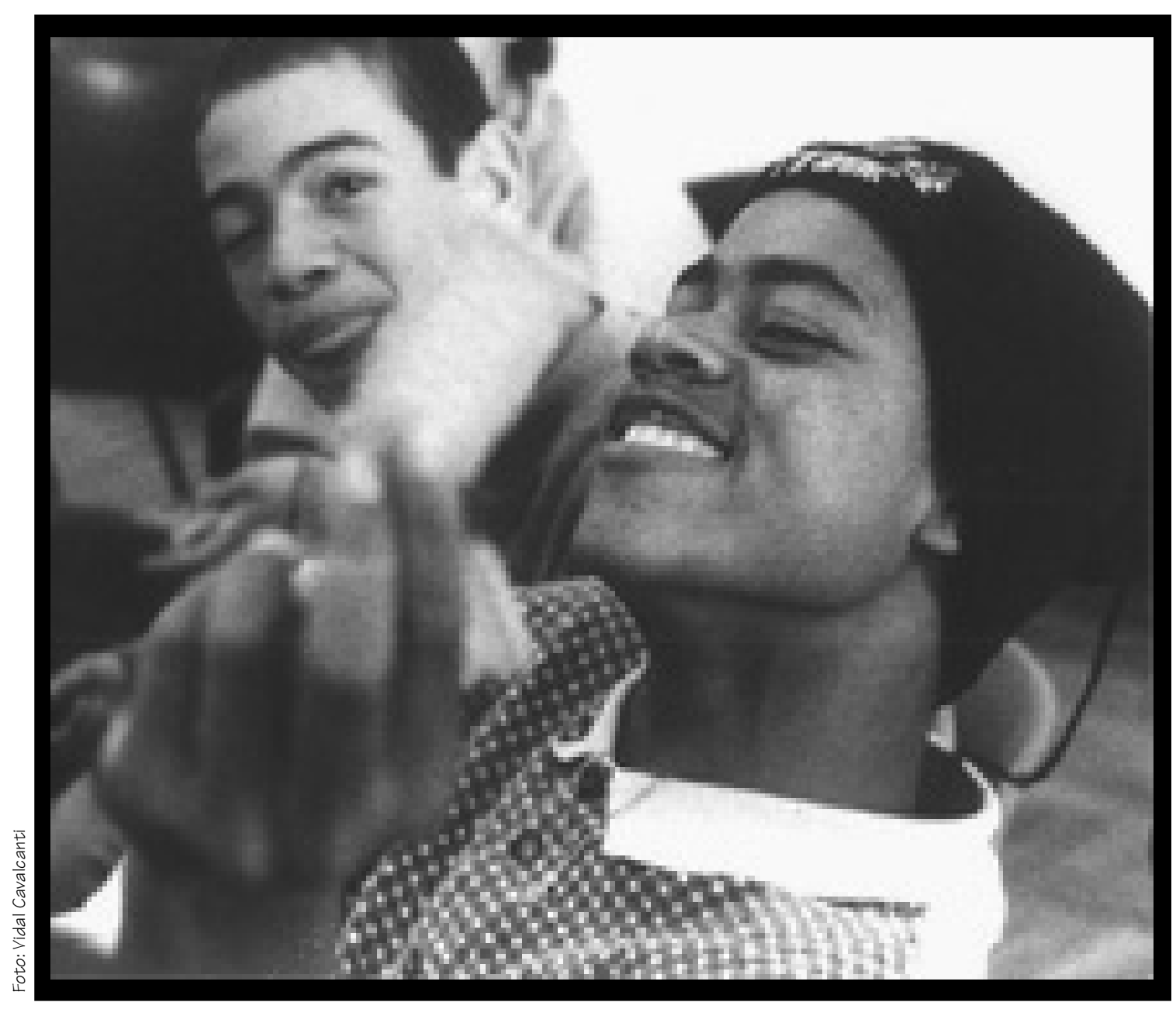




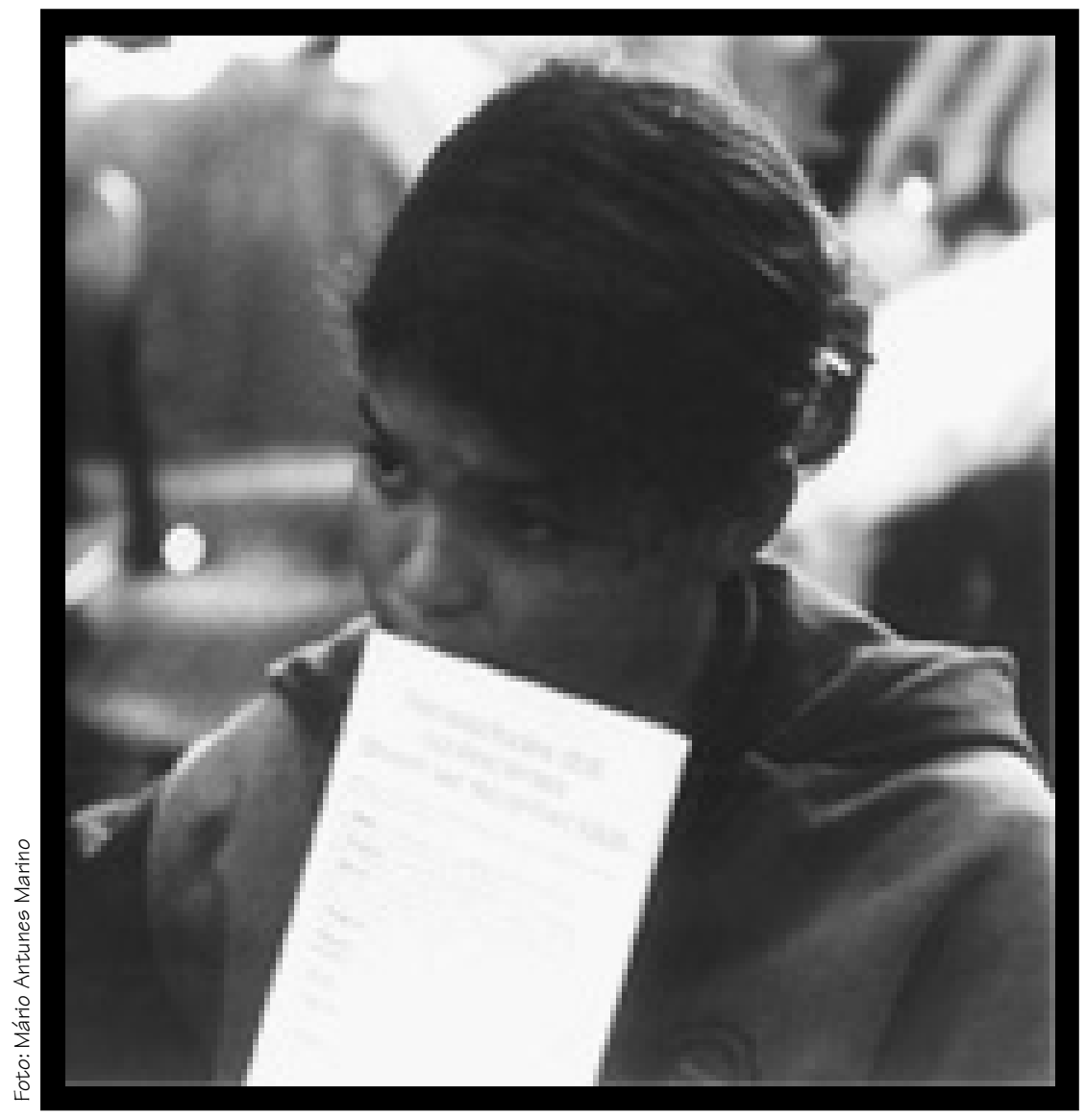

176 Interface - Comunic, Saúde, Educ 7 


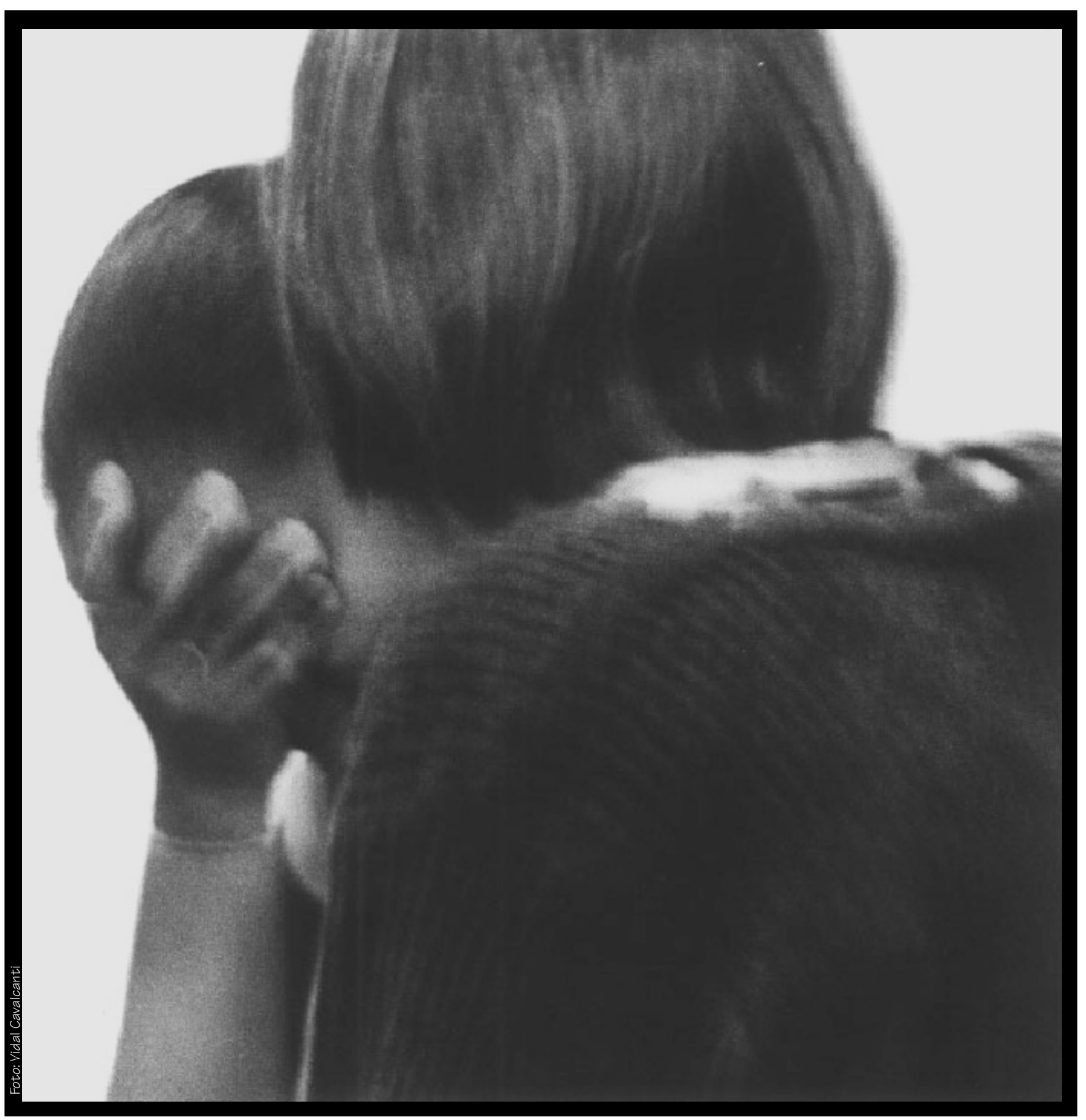


CRIAÇÃO

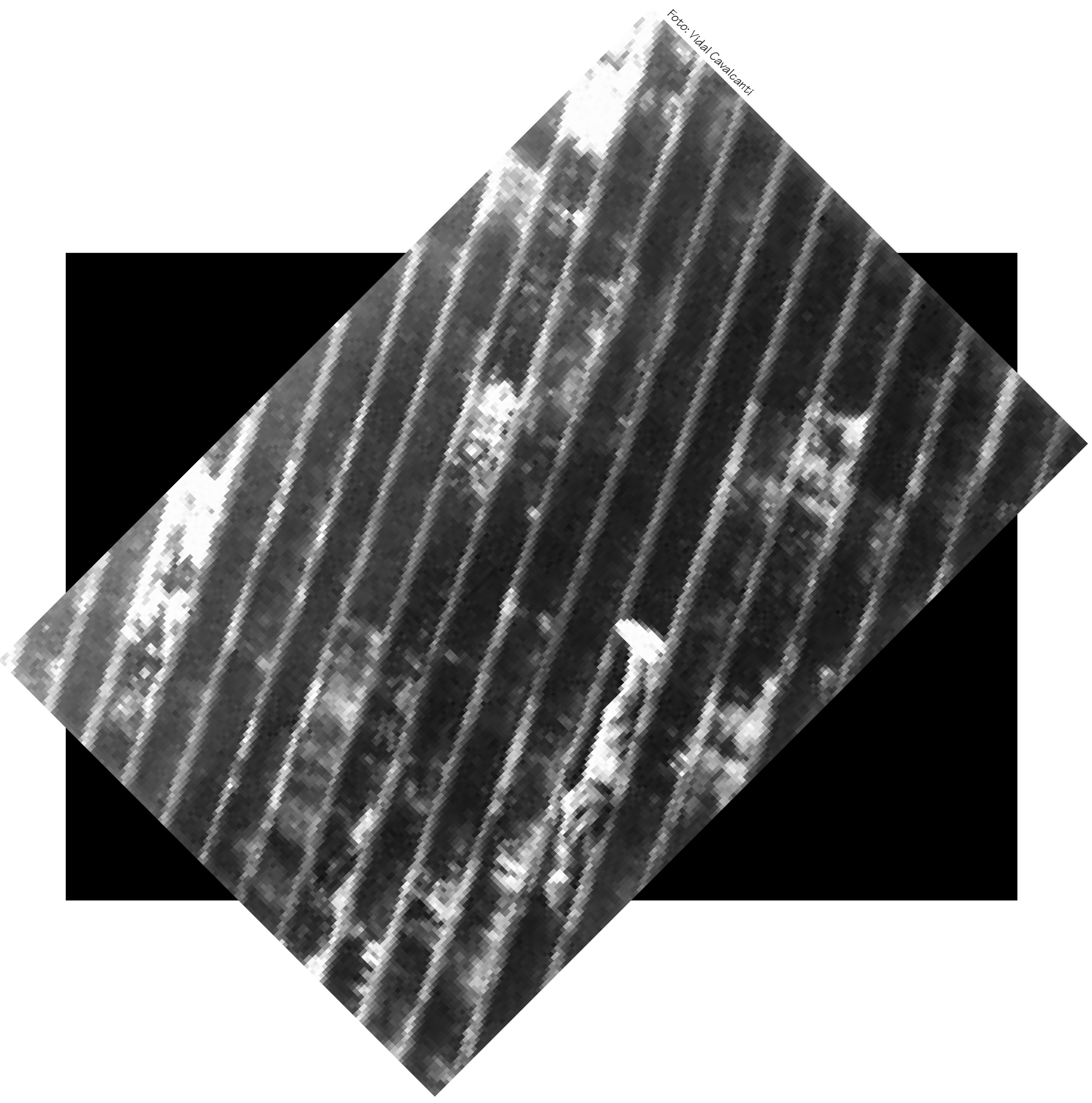

178 Interface - Comunic, Saúde, Educ 7 